\title{
GIS AND DWR BASED SHORT-TERM AND IMPENDING LANDSLIDE FORECASTING FOR LIANGSHAN PREFECTURE (CHINA)
}

\author{
Mingtao Ding, Fangqiang Wei
}

Original scientific paper Landslide forecasting for small and medium sized regions is taken as the subject matter. Liangshan Yi Autonomous Prefecture in Sichuan Province (China) as the study area. Geographic Information System (GIS) and Doppler Weather Radar (DWR) were used as the technologies. Eight influencing elements including slope gradient, stratigraphic lithology, land use, amount of precipitation, intensity of hourly precipitation, and proximity to the nearest fault, river, and road are the predictors. Information Model (IM), Fuzzy Mathematics (FM), and Extenics are the theoretical support in this paper, which builds a landslide forecasting model for small and medium sized regions and develops a GIS and DWR based short-term and impending landslide forecasting system on the ArcGIS 9.3 Platform for Liangshan Prefecture. The system provides a seamless rolling landslide forecast for Liangshan Prefecture, with a 1 $\mathrm{h}$ interval and a $3 \mathrm{~h}$ forecast period. The simulation results indicate that the system serves well in landslide forecasting for small and medium sized regions, and is thus applicable in the hazard forecasting practice at prefecture scale.

Keywords: DWR; forecasting system; landslide; small and medium sized regions

Kratkoročno predviđanje prijetećeg odrona zemlje na temelju GIS i DWR za prefekturu Liangshan (Kina)

Izvorni znanstveni članak Tema rada je predviđanje odrona zemlje za mala i srednje velika područja. Izabrana je autonomna prefektura Liangshan Yi u pokrajini Sichuan (Kina), kao istraživano područje. Geographic Information System (GIS) i Doppler Weather Radar (DWR) su rabljene kao tehnologije. Osam utjecajnih elemenata uključujući nagib padine, stratigrafsku litologiju, upotrebu zemlje, količinu padavina, intenzitet padavina po satu te udaljenost od najbližeg rasjeda, rijeke i ceste su prediktori. Information Model (IM), Fuzzy Mathematics (FM), i Extenics su teorijska podrška u ovom radu, u kojem se gradi model za predviđanje odrona u malim i srednje velikim područjima te razvija sustav za predviđanje mogućih, skorih odrona, zasnovan na GIS i DWR, na platformi ArcGIS 9.3 prefekture Liangshan. Sustavom se predviđa odron za prefekturu Liangshan s intervalom od 1 sata i vremenom predviđanja od 3 sata. Rezultati simulacije pokazuju da sustav može dobro poslužiti za predviđanje odrona u malim i srednje velikim područjima te je stoga primjenjiv za predviđanje opasnosti na razini prefekture.

Ključne riječi: DWR; klizišta; mala i srednja regije; prognostički sustav

\section{Introduction}

There are many categories of landslide forecasting, such as spatial, temporal, regional and fixed-point, to all of which great importance has long been attached. The short-term and impending refers to the landslide probability forecasting for different regions in the next several hours of imminent precipitation. It determines the key region and guides, from a macro perspective, the policymaking of landslide hazard reduction.

Being one of the significant landslide hazard reduction devices, landslide forecasting has aroused great concern from the international academia and national governments. Based on the intensity-duration relationship of multi-year mean daily rainfall, Wilson (1997) drew the contour of $24 \mathrm{hr}$ and $6 \mathrm{hr}$ rainfall thresholds, which has been used in landslide forecasting for the San Francisco Bay region [1]. Bell (2000) developed a critical precipitation coefficient for the Durban region of South Africa by analysing the relationship between mean annual rainfall and landslide occurrence [2]. Tan Wanpei (1994) furthered the research of critical precipitation value for valley-shaped debris flows and landslide initiation by applying statistical analysis of debris flow and landslide events in the Panzhihua-Xichang region [3]. Based on landslide and rainfall data of the Three Gorges region, Ding Jixin (2004) depicted quantificationally the susceptibility of rainfall-triggered landslides by analysing the landslide-rainfall relationship from 3 perspectives, namely the relationship between landslides and rainfall amount, rainstorms, and duration [4]. Taking Yucheng
District in Ya'an City of Sichuan as the study area, Li Yuan (2006) introduced Logistic Regression Model into the regional rainfall-triggered landslide early warning and forecasting, developing a rainfall critical value expression that covers rainfall intensity and process [5]. Instead of underlying surface conditions, the above-mentioned forecasts mainly depend on precipitation, thus are inapplicable for large-scale regions.

Due to the poor landslide predicting and forecasting accuracy and the uncertainty of precipitation forecasting, it is difficult to build a landslide forecast with certainty at present. However, in order to decrease casualties and economic loss to the greatest possible extent, it is a must to establish a short-term and impending landslide forecasting system for small and medium sized regions, supporting the government department of hazard reduction in policymaking. Selecting the severely landslide-stricken prefecture as the typical study area, DWR as the precipitation element acquiring means, and adopting a bi-layer model of IM and Extension Model (EM), this study establishes for the study area a forecasting system of landslide probability within a future several-hour period.

\section{Background of the study \\ 2.1 Study area}

Liangshan Yi Autonomous Prefecture (Fig. 1) is located in southwest Sichuan, China, with the Jinsha River in the south, the Dadu River in the north, the Sichuan Basin on the east, and the Hengduan Mountains 
on the west border. It is at $26^{\circ} 03^{\prime} \div 29^{\circ} 27^{\prime} \mathrm{N}$ and $100^{\circ} 15^{\prime} \div$ $103^{\circ} 53^{\prime} \mathrm{E}$, covering an area of $60100 \mathrm{~km}^{2}$.

Serving as a transition zone between the First and the Second Ladder-like Regions in China, it is defined by sharply undulating terrain and mountain landforms, mainly the high and mid mountains. There are both mountains and plains; and the former takes up approximately $70 \%$ of the total area. The elevation difference between the highest of $5958 \mathrm{~m}$ and the lowest of $305 \mathrm{~m}$ is $5653 \mathrm{~m}$. Such landforms provide sufficient energy and a venue for the full development of landslides.

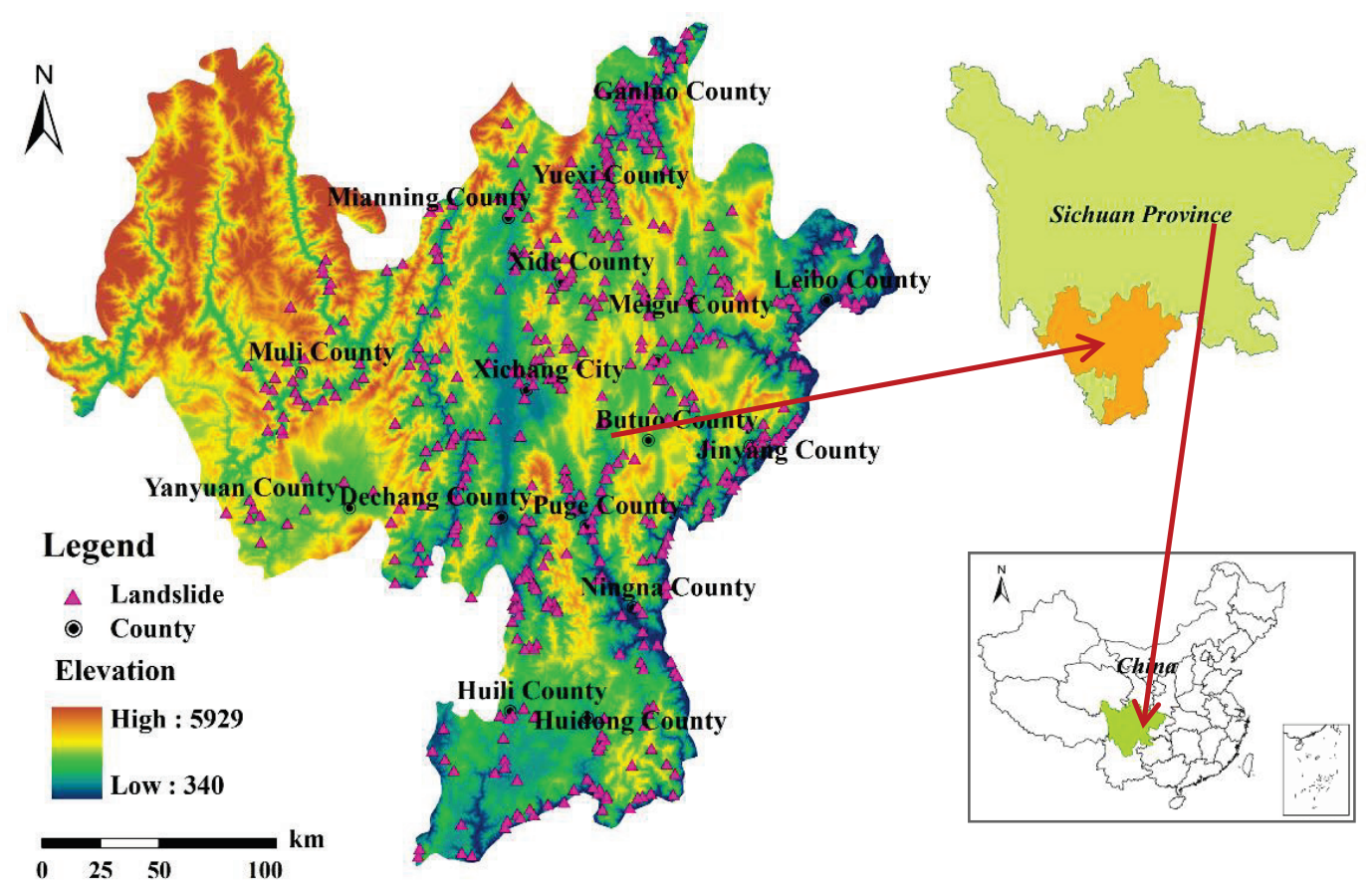

Figure 1The study area's location and landslide distribution

Situated in the middle section of Xikang-Yun'nan structural belt which is aligned in an almost NS direction, the study area has complicated geological structures, intense neotectonic movements, and frequent seismic activities. Variously originated loose deposits are well exposed with a full range of rocks, including sedimentary, metamorphic, and igneous ones. Faults and folds developed in diverse phases and directions further indicate the complicacy of geological history and the high frequency of rock mass being damaged by tectonic movements.

With subtropical monsoon climate, the area features obvious vertical zonality and two distinct seasons: the wet and the dry. During the wet season (May $\div$ October), precipitation exceeds $800 \mathrm{~mm}$, occupying $84 \div 95 \%$ of the annual amount; and it even reaches $1180 \mathrm{~mm}$ in some places. Abundant precipitation serves as a landslide trigger.

As mentioned above, the geological, landform, and precipitation conditions provide landslide development with materials, energy, and triggers. There are a total of 533 identified active landslide sites (Fig. 1), defining the study area as a typical landslide prone area.

\subsection{DWR}

Completed and put into practice in November 2004, the DWR station is located at $27^{\circ} 53^{\prime} \mathrm{N}, 102^{\circ} 25^{\prime} \mathrm{E}$ and equipped with $2702,7 \mathrm{~m}$ antennae. Each radar scan lasts for $6 \mathrm{~min}$, with an echo covering almost the entire prefecture. DWR can recognize, predict and forecast severe convective weather like storm, hail, and tornado, producing precipitation data with high accuracy, fast upgrades, spatial continuity, and $1 \mathrm{~km}$ ground spatial resolution.

\subsection{Data resources}

Data sources in this study include (1) 1: 50000 digital topographical map of Liangshan Prefecture (Vector data), (2) 1:200000 digital geological map of Liangshan Prefecture (Vector data), (3) 1:100 000 land use map of Liangshan Prefecture (Vector data), (4) DWR maps 21\#, $57 \#$, and 78\# (Raster data), (5) observed precipitation by Meteorological Stations (MS) of the prefecture, (6) occurred landslide events with identified time and places.

\section{Regional short-term and impending landslide forecasting model}

Statistical data of the 533 sites show that $85 \%$ of the active landslides have a spatial size smaller than $100 \times$ $100 \mathrm{~m}$. Therefore, a $100 \times 100 \mathrm{~m}$ unit size is adopted to simplify calculation, avoid misstatement or omission, and improve precision and accuracy of landslide forecasting.

Predictor selection plays a vital role in regional landslide forecasting. Two aspects should be taken into account: one is underlying surface, i.e. the most favourable location for landslide occurrence; the other is precipitation. According to the study area's actual situation, six underlying surface elements (slope gradient, stratigraphic lithology, land use, proximity to the nearest fault, river, and road) and two precipitation elements (amount of precipitation and hourly precipitation intensity) 
are selected. Concerning the bi-layer model, IM is applied in analysing the most favourable ground elements for landslide occurrence; while EM in probability forecasting by combining ground and precipitation elements.

Considering landslide features, the forecasting model utilizes methods as follows:

The first step: processing the underlying surface elements with IM; extracting the information content (IC) from every single-factor map; superposing the corresponding grid of different maps to obtain a comprehensive IC map of the entire study area, i.e. the landslide susceptibility score plot.

The second step: using FM and extension theories, landslide susceptibility, amount of precipitation, and hourly precipitation intensity to develop a standard matter-element model of landslide probability; calculating the degree of correlation between any combination state of the three predictors and the corresponding state in the model; and determining the landslide probability under the Maximum Subordination Degree (MSD) principle.

\subsection{IM}

Among influencing element combinations, there always exists, for landslide initiation, an "optimal one" with the greatest "contributing rate"; and the regional "optimal landslide element combination" is analysed in this paper through IM [6].

In the information prediction viewpoint, landslide occurrence is related to both information quantity and quality in the prediction process, which can be measured by IC:

$$
I\left(Y, X_{1} X_{2} \cdots X_{n}\right)=\ln \frac{P\left(Y, X_{1} X_{2} \cdots X_{n}\right)}{P(Y)} .
$$

According to Condition Probability, the above formula can be rewritten as:

$$
\begin{aligned}
& I\left(Y, X_{1} X_{2} \cdots X_{n}\right)= \\
& =I\left(Y, X_{1}\right)+I_{X_{1}}\left(Y, X_{2}\right)+\cdots+I_{X_{1} X_{2} \cdots X_{n-1}}\left(Y, X_{n}\right) .
\end{aligned}
$$

In the formula: $I\left(Y, X_{1} X_{2} \ldots X_{n}\right)-$ geological hazard IC provided by the element combination $X_{1} X_{2} \ldots X_{n}$,

$P\left(Y, X_{1} X_{2} \ldots X_{n}\right)-$ geological hazard probability with the element combination $X_{1} X_{2} \ldots X_{n}$,

$I X_{1}\left(Y, X_{2}\right)$ - geological hazard IC provided by Element $X_{1}$, with the existence of $X_{2}$,

$P(Y)$ - geological hazard probability.

The modelling process is as follows:

(1) Calculating independently $I\left(x_{i}, H\right)$, i.e. IC of the landslide event $(H)$ provided by Element $x_{i}$ :

$$
I\left(x_{i}, H\right)=\ln \frac{P\left(x_{i} \mid H\right)}{P\left(x_{i}\right)} .
$$

In the formula: $P\left(x_{i} \mid H\right)$ is xi's appearing probability when landslide distribution is integrated; $P\left(x_{i}\right), x_{i}$ 's appearing probability in the study area.

Eq. (3) is the theoretical model; and in practice, the following sampling frequency is often used:

$$
I\left(x_{i}, H\right)=\ln \frac{N_{i} / N}{S_{i} / S}
$$

In the formula: $S$ is the total number of assessment units in the study area; $N$, that of landslide distributed units; $S_{i}$, that of $x_{i}$-containing units; and $N_{i}$, that of landslide units with $\mathrm{x}_{\mathrm{i}}$.

(2) Calculating the total IC value of each individual assessment unit:

$I_{i}=\sum_{i=1}^{n} I\left(x_{i}, H\right)=\sum_{i=1}^{n} \ln \frac{N_{i} / N}{S_{i} / S}$

In the formula: $I_{i}$ is the total IC value of an assessment unit; $\mathrm{n}$, the assessment element number.

(3) Taking $\sum I_{i}$, the total IC of the unit as a comprehensive index of landslide occurrence. The larger it is, the more favourable for landslides the unit, and the higher the landslide susceptibility.

\section{$3.2 \mathrm{EM}$}

Initiated with the transformation law and the solution of incompatibility problems, Extenics [7] abstracts realworld objects into a triad of object, characteristic, and the object's value concerning the characteristic. Introducing the matter-element concept and adopting conversion and calculation, it studies and solves incompatibility problems from qualitative and quantitative perspectives. The theories of matter-element and extension set [8] are the basis for the regional landslide forecasting; FM the means to transform qualitative indexes into quantitative ones.

Landslide forecasting means predicting landslide probability during a future period and under certain circumstances. Its results should be a kind of prediction with probability significance. However, current landslide forecasting models are incapable of accurately determining the probability. Therefore, instead of being directly expressed by probabilities, the results should be generalized into five grades through FM methods. With each representing an interval of landslide probabilities, they are listed from the first to the fifth: $<0,0 ; 0,2>,<0,2$; $0,4>,<0,4 ; 0,6>,<0,6 ; 0,8>,<0,8 ; 1,0>$.

A landslide results from the precipitation effect upon underlying surfaces. With available underlying surface susceptibility, it is possible to analyse and assess the probability of landslides occurring on underlying surfaces with different precipitation effects, i.e. the regional landslide forecasting results. Landslide susceptibility gained through the analysis of six underlying surface predictors, together with the amount of precipitation and hourly precipitation intensity, is regarded as the ultimate predictor.

$B_{j}(j=1,2,3 \ldots m)$, the landslide probability grade varies with different combination states of $X_{a}$ (landslide susceptibility), $X_{1}$ (amount of precipitation), and $X_{2}$ (hourly precipitation intensity). A matter-element model of $B_{j}$ (landslide probability) should be developed first, so as to determine the value of $B_{j}$ in combination states: $R\left(X_{a}\right.$ $\left.\mathrm{X}_{1}, X_{2}\right)=R$ (underlying surface susceptibility to landslide, amount of precipitation, hourly precipitation intensity). 


$$
R_{0}=\left[\begin{array}{ccc}
B, \text { landslide probability } & \mathrm{X}_{\mathrm{a}} & x_{a} \\
& \mathrm{X}_{1} & x_{1} \\
& \mathrm{X}_{2} & x_{2}
\end{array}\right]
$$

In the formula: $x_{a}, x_{1}, x_{2}$ are respectively the dimensionless value of $X_{a}, X_{1}, X_{2}$ through subordination.

Then the degree of correlation between $R$ and $R_{0}$ (the corresponding state in the standard matter-element model with $B_{j}$ ) can be calculated. $K(x)$ is the degree of correlation between $B_{j}$ and every predictor in $R$.

$$
K(x)=\frac{\rho\left(x, X_{0}\right)}{D\left(x, X_{0}, X\right)} .
$$

$X_{0}=\langle a, b\rangle, X=\langle c, d\rangle, X_{0} \subset X, X_{0}$ is the classical domain, and $X$ the joint one.

$$
\begin{aligned}
& \rho\left(x, X_{0}\right)=\left|x-\frac{a+b}{2}\right|-\frac{1}{2}(b-a) \\
& D\left(x, X_{0}, X\right)=\left\{\begin{array}{c}
\rho(x, y)-\rho\left(x, X_{0}\right), x \notin X_{0} \\
-1, x \in X_{0}
\end{array} .\right.
\end{aligned}
$$

$K_{j}(P)$ is the degree of correlation between $R$ and $B_{j}$,

$$
K_{j}(P)=\sum_{i=1}^{8} \alpha_{i} K_{j}\left(x_{i}\right)
$$

In the formula, $\alpha_{i}$ is the weight of $X_{i}$ among other elements; $K_{j}\left(x_{i}\right)$ the degree of correlation between $X_{i}$ and $B_{j}$.

Landslide probability can be gained through Eq. (8) in accordance with the MSD principle. $B_{k}$ is the landslide probability in $R$, if $K_{k}(P)=\max _{k \in\{1,2, \cdots, m\}} K_{j}(P)$.

\section{Landslide predictor selecting and data processing 4.1 Underlying surface influencing elements}

Combining natural geographical features of the study area and giving full consideration to factors like data accessibility, scale of the study area, and required precision, this study selects six influencing elements including slope gradient, stratigraphic lithology, land use, proximity to the nearest fault, river, and road as major assessment indexes of the ground state $[9,10]$.

\subsubsection{Slope gradient}

It is a major element for landslide occurrence. Together with its increase, shearing forces including gravity, and hence the landslide probability also rise. Places with large slope gradient are often landslip venues, providing materials for and finally triggering landslides.

The 1:50,000 topographical map is used as base graph, from which the digital contour data are obtained by vector processing and quality controlling. Digital Elevation Model (DEM) of the study area is then established through GIS; and the slope gradient distribution map gained through the advanced spatial analysis function of GIS.

\subsubsection{Stratigraphic lithology}

The 1:200000 geological map issued by China Geological Survey (and Provincial Geology Bureau) is taken as base graph. By vectorizing the map's stratum data in GIS and adding their stratum codes and stratigraphic lithology illustration into the corresponding attribute database, raw strata data are gained.

Table 1 Quantitative stratigraphic lithology grading standards

\begin{tabular}{|c|c|c|c|}
\hline \multirow{2}{*}{$\begin{array}{c}\text { Grading } \\
\text { value }\end{array}$} & Sedimentary rocks & Magmatic rocks & Metamorphic rocks \\
\cline { 2 - 4 } 1 & $\begin{array}{c}\text { Dolomite; dark-grey, thick } \\
\text { bedded limestone; oncolitic, } \\
\text { siliceous, and cherty limestone }\end{array}$ & $\begin{array}{c}\text { Thick bedded acid rocks (thick } \\
\text { bedded rhyolite, andesite, etc.) }\end{array}$ & Quartzite; quartz vein; diabase; diabase vein \\
\hline 2 & $\begin{array}{c}\text { Quartz sandstone; siliceous } \\
\text { conglomerate; light-colored } \\
\text { limestone; quartz siltstone }\end{array}$ & $\begin{array}{c}\text { Fine-grained granite; diorite; gabbro; } \\
\text { andesite; basalt; tuff; rhyolite } \\
\text { porphyry; basic igneous rock } \\
\text { (gabbro); ultrabasic (peridotite); } \\
\text { alkalic (orthoclase); diabase; } \\
\text { porphyrite }\end{array}$ & Marble; quartz schist; amphibolite; serpentinite \\
\hline 3 & $\begin{array}{c}\text { Sandstone; siltstone; marlite; } \\
\text { sandy, siliceous mudstone; } \\
\text { conglomerate }\end{array}$ & $\begin{array}{c}\text { Pyroclastic rock; porphyritic, coarse- } \\
\text { grained granite; orthophyre }\end{array}$ & Schist; slate; granulite; metabasalt; metarhyolite; \\
metasand-stone; gneiss
\end{tabular}

There has been a lack of sound quantification and utilization methods to apply stratigraphic lithology in landslide research on susceptibility, risk assessment, etc. Lithology Grading Method by Fangqiang Wei (2008) [11] is adopted in this study. Its principles include: (1) grading by rigidity and (2) water absorption capacity; (3) modifying with strata reference. The descending order of strata (in terms of contribution to landslides) is: 
Quaternary - Cenozoic (Tertiary) - Precambrian Proterozoic - Paleozoic - Mesozoic.

According to the rock stratum grading features, quantification and classification of stratum indexes are directly carried out in the map. High scores are assigned to those with great contribution in material accumulation and landslide occurrence; and low scores to others with small contribution. The quantitative stratigraphic lithology grading standards are thus made (Tab. 1).

\subsubsection{Proximity to the nearest fault}

The 1:200 000 geological map by China Geological Survey (and Provincial Geology Bureau) is applied as base graph, whose fault elements are vectorized in GIS. Based on the study area's geological environment, this study uses proximity to the nearest fault to well reflect the fault-landslide relationship. With the GIS distance analysis tool, distance between any spot in the study area and the nearest fault can be calculated. Thus the fault distance data of every landslide site is obtained by introducing the landslide distribution map through spatial analysis.

\subsubsection{Land use}

It is used to measure the human effect on landslides, which are basically a natural geological process. Influenced by human activities, however, landslides become more active than they are in the natural condition. Contribution of different land use types to landslide occurrence varies. The 1:100,000 land use map compiled by Ministry of Land and Resources is the base graph in this study. Land use data are thus gained through digitalization, edition and revision, and map sheet merging. In accordance with the national land use classification system, lands are grouped into seven types by considering, in a comprehensive manner, their contribution to the loose deposit formation: forestland, grassland, arable land, water area, residential and industrial land, bare land, glacier, shoaly land, bottomland, gebi desert, and saline-alkali land. Accordingly, weights are assigned to them (Tab. 2).

Table 2 Grouping and weight-assigning of 51 land use types

\begin{tabular}{|c|c|c|c|c|c|c|c|}
\hline $\begin{array}{c}\text { Grouped land } \\
\text { use types }\end{array}$ & Forestland & Grassland & $\begin{array}{c}\text { Arable } \\
\text { land }\end{array}$ & $\begin{array}{c}\text { Water } \\
\text { area }\end{array}$ & $\begin{array}{c}\text { Residential and } \\
\text { industrial land }\end{array}$ & $\begin{array}{c}\text { Bare land, } \\
\text { glacier }\end{array}$ & $\begin{array}{c}\text { Shoaly land, bottomland, gebi } \\
\text { desert, saline-alkali land }\end{array}$ \\
\hline Weights & 0,05 & 0,15 & 0,25 & 0 & 0,2 & 0,25 & 0,1 \\
\hline
\end{tabular}

\subsubsection{Proximity to the nearest river and road}

When an excavated or undercut basal slope weakens or breaks the link between sliding-prone strata and surrounding rock mass, landslides do occur if the prerequisite of having sufficient free surface in front is met and the sliding surface is exposed or sheared out. It can be seen from the landslide distribution that it is precisely because the basal mountain slope is undercut by rivers or excavated by road builders that there are so many free surfaces and hence landslides in the study area. Therefore, it is necessary to take into account the proximity to rivers and roads.

With the 1:50000 topographical map as base graph, river and road information are extracted through vectorizaiton; and the distribution data generated. Then the shortest distance between any spot in the study area and the nearest river or road is gained through the GIS spatial analysis function.

\subsection{Precipitation elements}

Such elements include antecedent, current, and forecast precipitation, all of which should be processed before use.

Antecedent and current precipitation: The antecedent mount of precipitation is part of the precipitation predictor. In the forecasting process, it is accumulated by the Rainfall Observation Station (ROS) amount during 20 days before the forecast period. Only the effective amount taking attenuation into account can be used [12]. The calculation formula by Seo Katsumi (1985) is applied:

$R_{\mathrm{a}}=\sum_{t=1}^{20} a_{t} R_{t}$.
$R_{\mathrm{t}}$ is the amount of precipitation observed at $\mathrm{MS}$, on the $t^{\text {th }}$ day before the forecast period;

$a_{\mathrm{t}}=0,5^{t / T}$ is the attenuation rate of precipitation; $T$ the half life, varying with different regional conditions.

Current precipitation is composed of two parts: the observed amount during the earlier period of the day and the hourly amount (OHP, 78\#) predicted by DWR for the rest of the day.

DWR forecast precipitation [13]: DWR can quickly and accurately capture regional severe convective weather, producing precipitation monitoring and forecasting maps with high-precision and $1 \mathrm{~km}$ ground spatial resolution. Forecast precipitation amount and hourly precipitation intensity during the forecast period $(3 \mathrm{hr})$ can be obtained by analysing and processing the DWR radar echo intensity map ( $\mathrm{dB}, 21 \#)$ (Fig. 2) and the vertically accumulated liquid map (VIL, 57\#) (Fig. 3) through the following methods:

The geometric conversion of images in map $21 \#$ and $57 \#$ are carried out through Eq. (10).

$\left\{\begin{array}{l}X=A x+B y+C \\ Y=D x+E y+F\end{array}\right.$.

In the formula: $X$ and $Y$ are ground coordinates; $x$ and $y$ are image coordinates; $A, B, C, D, E$ and $F$ are conversion coefficients [14].

By selecting no fewer than 3 image points (control points) of the known ground coordinate in radar images, substituting their image coordinates and corresponding ground coordinates into Eq. (10), equations and hence the least square solutions of six conversion coefficients $(A, B$, $C, D, E$ and $F$ ) are obtained. Then the mapping of radar image point coordinates and the corresponding ground 
ones is established though absolute orientation of radar images.

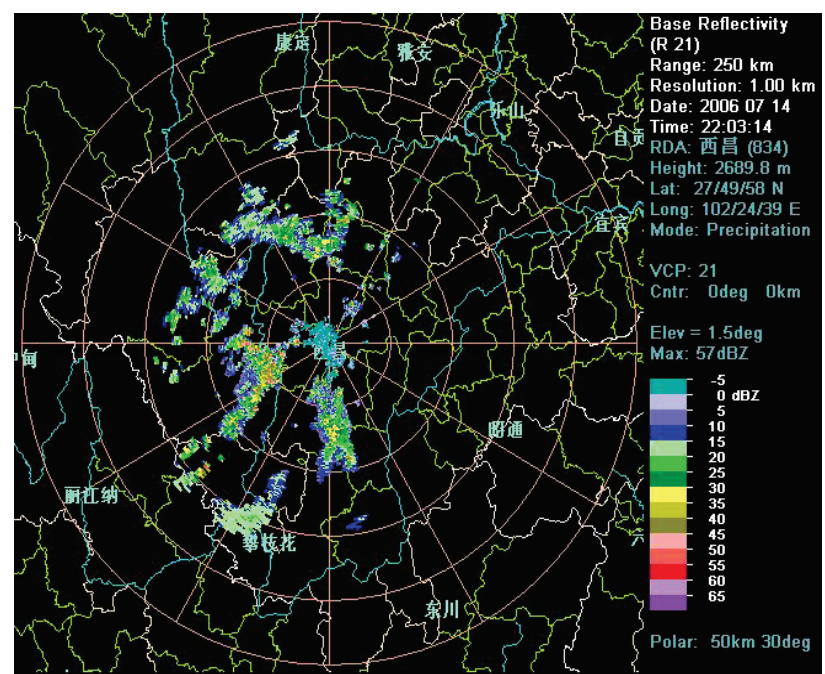

Figure 2 DWR map of Xichang City, 21\#, obtained at 22:00, $14^{\text {th }}$ July, 2006

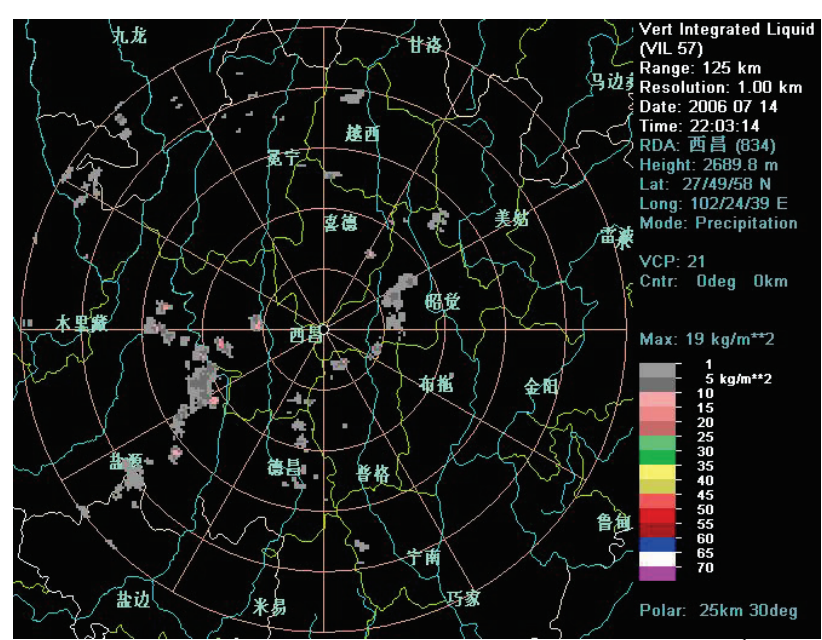

Figure 3 DWR map of Xichang City, 57\#, obtained at 22:00, $14^{\text {th }}$ July, 2006

According to the statistical data analysis, Map 21\# makes two thirds of the contribution, in calculating forecast precipitation amount and precipitation intensity; and 57\#, one third. Being assigned weight, both maps are used in producing calculation results that reflect the actual situation in a more objective manner.

\subsection{Procedure of processing landslide forecasting system data}

Using the ArcGIS9.3-based short-term and impending landslide forecasting system for Liangshan Prefecture to read data from Map 21\# and 57\#; assigning a 2/3 to 21\# and a $1 / 3$ to $57 \#$, according to the established mapping relationship between image point coordinates and ground ones; and gaining the forecast precipitation amount and precipitation intensity through accumulation.

Reading from the observed precipitation database the amount of precipitation during the 20 days before the forecast period; obtaining the effective antecedent precipitation amount through Eq. (9).

Reading from the same database the observed precipitation amount during the earlier period of the current day; combining it with the OHP predicted amount to obtain the current precipitation amount; gaining the precipitation predictor, i.e. the accumulative value of forecast, current and effective antecedent precipitation amount.

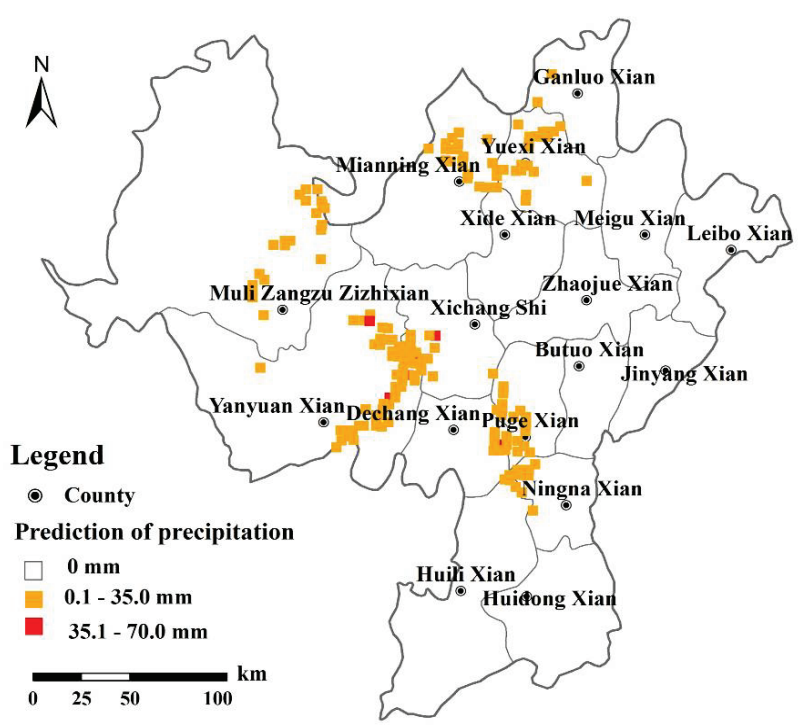

Figure 4 Precipitation in Liangshan Prefecture during the next 3 hours, forecast at 22:00, $14^{\text {th }}$ July, 2006

Calculating dimensionless values of the landslide predictors by linear relationship and subordination degree; classifying them into five grades in correspondence with the five forecasting result grades; listing their intervals in an ascending order: $\langle 0,0 ; 0,2>,<0,2 ; 0,4>,<0,4 ; 0,6>$, $<0,6 ; 0,8>,<0,8 ; 1,0>$. Gaining the degree of correlation between each predictor and result grade through Eq. (7); Under the MSD principle, using Eq. (8) to determine the landslide probability of every unit, define the forecasting result grades, and compile the forecasting map.

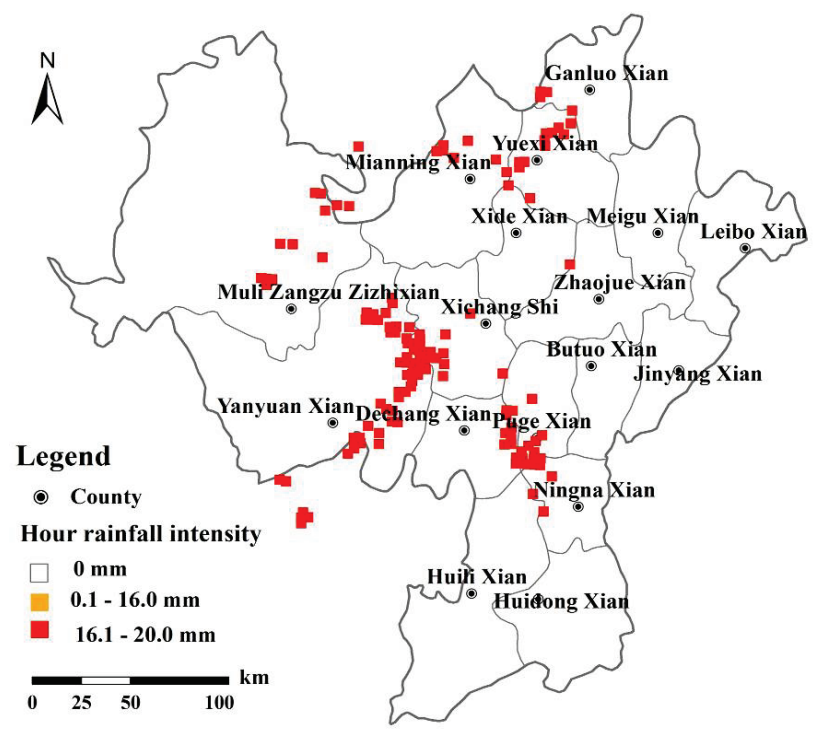

Figure 5 Precipitation intensity, forecast at 22:00, 14 ${ }^{\text {th }}$ July, 2006

\section{Application case}

Severe landslides hit Luomabao Village, Pingchuan Town, Yanyuan County in the study area, 23:00, $14^{\text {th }} \div$ $1: 00,15^{\text {th }}$ July, 2006. Based on the DWR monitoring data 
obtained at 22:00 $14^{\text {th }}$, the forecasting system works out the forecast precipitation amount (Fig. 4) and the hourly precipitation intensity (Fig. 5) in the next 3 hours. A map forecasting landslides in the next 3 hours is accordingly made (Fig. 6). The Grade-4 results (with the landslide probability of $0,6 \div 0,8$ ) for the landslide-stricken region proves the reliability of the forecasting system.

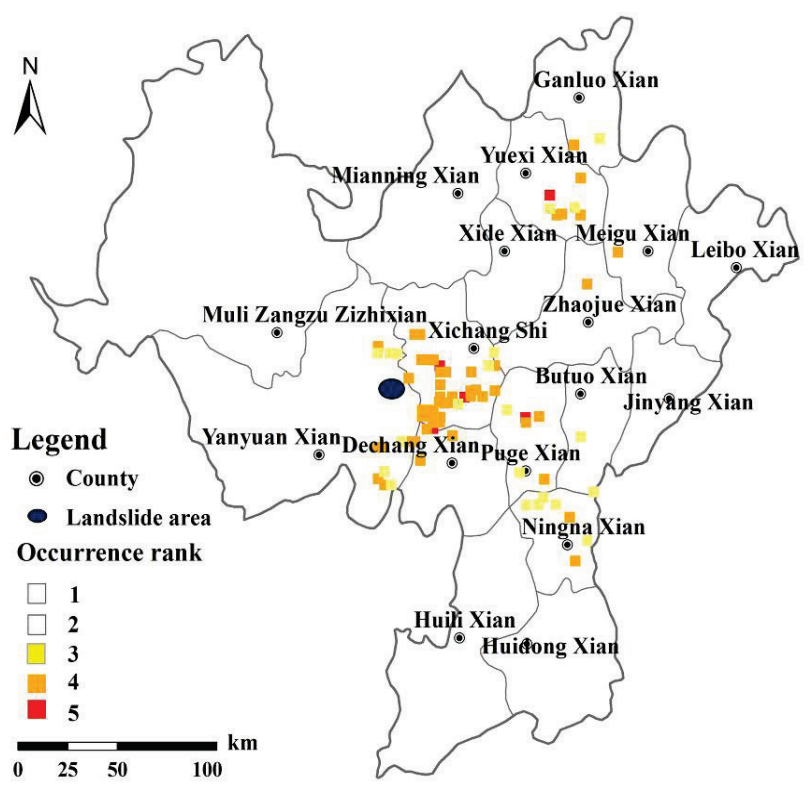

Figure 6 Landslide forecasting map, compiled at 22:00, $14^{\text {th }}$ July, 2006

\section{Conclusion and discussion}

By examining the forecasting methods and the operating results, a conclusion can be drawn as follows:

(1) At present, no breakthroughs have been achieved by forecasting models based on landslide formation mechanism. On the contrary, the IM and EM based model can better solve the problem of regional landslide forecasting through origin analysis.

(2) Featured by fast upgrades, high resolution and precision, DWR provides effective precipitation monitoring and forecasting means to short-term and impending landslide forecasting for small and medium sized regions, greatly improving its accuracy.

This system achieved sound effect in its trial operation.

However, it needs more cases for verification. Therefore, it is necessary for the following two aspects to be further improved:

(1) Since landslide data of the study area are limited, more cases are needed for the verification of forecasting accuracy and the modification of forecasting predictors, making the results closer to the actual situation.

(2) Due to the scarce ROS distribution and the short operation period of DWR, data accumulation and radar "localization" are both insufficient, leaving room for further improvement, especially in acquiring accurate precipitation amount and intensity.

\section{Acknowledgment}

The study was financially supported by the National Natural Science Foundation of China (Grant No. 41371185 and 41101164), the project of Science and
Technology Department of Sichuan Province (Grant No. 2013HH0057) and the key project of Education Department of Sichuan Province (Grant No. 13ZA0160).

\section{References}

[1] Wilson, R. C. Normalizing rainfall / debris-flow thresholds along the U.S. pacific coast for long-term variations in Precipitation Climate. // Cheng-lung Chen, Debris-flow hazard mitigation: Mechanics, Prediction, and Assessment, 1997, pp. 32-43.

[2] Bell, F. G.; Maud, R. R. Landslides associated with the colluvial soils overlying the Natal Group in the greater Durban region of Natal, South Africa. // Environmental Geology. 39, 9(2000), pp. 1029-1038. DOl: $10.1007 / \mathrm{s} 002549900077$

[3] Wanpei, Tan; Qingyu, Han. Study on regional critical rainfall indices of debris flow in Sichuan province. // Journal of catastrophology. 7, 2(1992), pp. 37-42. (in Chinese)

[4] Jixin, Ding; Yanjun, Shang; Zhifa, Yang. New method of prediction rainfall-induced landslides. // Rock Mechanics and Engineering. 23, 21 (2004), pp. 3738-3743. (in Chinese)

[5] Yuan Li, Xudong Yang. Research on the forecasting and early warning of the regional precipitation-induced landslide. // Hydrogeology and Engineering Geology. 30, 4, (1999), pp. 273-277. (in Chinese)

[6] Kechang, Gao; Peng, Cui; Chunyong, Zhao. Landslide hazard evaluation of Wanzhou based on GIS information value method in the Three Gorges reservoir. // Rock Mechanics and Engineering. 25, 5(2006), pp. 991-996. (in Chinese)

[7] Wen, Cai; Chunyan, Yang; Weichu, Lin. Extension Engineering Method. // Beijing: Science Press, 2000. (in Chinese)

[8] Lehong, Kuang; Baochen, Liu; Jingchen, Yao. Research on Regionalization of Debris Flow Risk Degree with Fuzzy and Extension Method. // Journal of Catastrophology. 21, 1(2006), pp. 68-72. (in Chinese)

[9] Fangqiang, Wei; Pengcheng, Su; Yuhong, Jiang. Distribution characteristics of landslides and debris flows in the Wenchuan earthquake region before and after the earthquake. // Disaster advances. 5, 4(2012), pp. 285-294.

[10] Mingtao, Ding; Fangqiang, Wei. Distribution Characteristics of Debris Flows and Landslides in Three Rivers Parallel Area. // Disaster advances. 4, 3(2011), pp. 714.

[11] Fangqiang, Wei; Kechang, Gao; Kaiheng, Hu. Relationships between debris flows and earth surface factors in Southwest China. // Environmental Geology. 55, 3(2008), pp. 619-627. DOI: 10.1007/s00254-007-1012-3

[12] Fangqiang, Wei; Kaiheng, Hu; Jie Chen. Determination of Effective Antecedent Rainfall for Debris Flow Forecast. // Journal of Mountain Science. 23, 4(2005), pp. 453-457. (in Chinese)

[13] Yuhong, Jiang; Fangqiang, Wei; Jinghong, Zhang. Regional prediction of impending debris flow based on doppler weather radar. // Wuhan University Journal of Natural Sciences. 12, 4(2007), pp. 627-632. DOI: 10.1007/s11859006-0325-5

[14] Kangtsung, Chang. Introduction to Geographic Information Systems. // Beijing: Science Press, 2003. (in Chinese) 


\section{Authors' addresses}

Mingtao Ding, Associate Professor

School of Environment and Resource,

Southwest University of Science and Technology

Sichuan Mianyang 621010, China

E-mail: mingtaoding@gmail.com

Fangqiang Wei, Professor

Institute of Mountain Hazards and Environment,

Chinese Academy of Sciences

Sichuan Chengdu 610041, China

E-mail: fqwei@imde.ac.cn 